\title{
$\underline{\text { AARC standards for multicultural research }}$
}

By: Caroline O’Hara, Madeline Clark, Danica G. Hays, C. Peeper McDonald, Catherine Y. Chang, Stephanie A. Crockett, Joel Filmore, Tarrell Portman, Shawn Spurgeon, and Kelly $\underline{\text { Wester }}$

O’Hara, C., Clark, M., Hays, D. G., McDonald, C. P., Chang, C. Y., Crockett, S. A., Filmore, J., Portman, T., Spurgeon, S., \& Wester, K. L. (2016). AARC standards for multicultural research. Counseling Outcome Research and Evaluation, 7, 67-72.

Made available courtesy of SAGE: $\underline{\text { https://doi.org/10.1177/2150137816657389 }}$

***(C) 2016 The Authors. Reprinted with permission. No further reproduction is authorized without written permission from SAGE. This version of the document is not the version of record. Figures and/or pictures may be missing from this format of the document. ***

\begin{abstract}
:
The impetus for creating the Standards for Multicultural Research is based upon the idea that multicultural competence continues to evolve as research and evidence-based practices inform the profession of counseling. These standards aim to address research that focuses on multiculturalism as well as general multicultural considerations in research. The goal is to promote cultural intentionality, inclusion, and responsiveness. As such, the development of these standards is an attempt to address the potential obstacles, challenges, and rewarding aspects of developing and producing research that is multiculturally competent.
\end{abstract}

Keywords: diversity | multiculturalism | counseling | research standards

\section{Article:}

Developed by the Association for Assessment and Research in Counseling (AARC) Diversity Committee, 2013-2016

Chair: Caroline O'Hara

Members: Madeline Clark, Danica G. Hays, C. Peeper McDonald, Catherine Y. Chang, Stephanie A. Crockett, Joel Filmore, Tarrell Portman, Shawn Spurgeon, Kelly L. Wester

\section{Purpose}

The impetus for creating the Standards for Multicultural Research is based upon the idea that multicultural competence continues to evolve as research and evidence-based practices inform the profession of counseling. These standards aim to address research that focuses on multiculturalism as well as general multicultural considerations in research. The goal is to promote cultural intentionality, inclusion, and responsiveness. As such, the development of these standards is an attempt to address the potential obstacles, challenges, and rewarding aspects of developing and producing research that is multiculturally competent. 
Consequently, this document will provide minimum and current standards of practice. Professional counselors, counselor educators, and counseling researchers are continually encouraged to utilize these standards and seek out best practices related to research and multiculturalism. Finally, this document is expected to be updated over time, as ideas around multiculturalism evolve and influence the nature of research practices in professional counseling and counselor education.

\section{Definitions of Diversity, Multiculturalism, and Marginalized Populations}

Whereas diversity includes the vast similarities and differences across cultural and social identities, multiculturalism acknowledges and affirms diverse individuals within their unique contexts. Marginalized populations include, but are not limited to, individuals and groups that have historical and/or current experiences with systematic oppression based on their ability status, age, country of origin, ethnicity, gender, gender identity, language preference, race, religious or spiritual affiliation, sexual identity, and/or social class. In many cases, identities may be intersectional and may include multiple heritages. In addition, it is important to note that individuals and groups may experience marginalization due to external assumptions about their identities - assumptions that may or may not be accurate.

\section{Definitions of Social Justice and Advocacy}

Social justice relates to empowerment, access to resources, equity, distributive justice, and the ability of people to participate in the systems that influence their lives. Advocacy involves breaking down barriers to wellness, acting to dismantle systems of privilege and oppression, and working for and with marginalized populations to effect change and promote development. Thus, social justice can be viewed as a goal; advocacy is a means by which to achieve that goal.

\section{The Standards}

Advocacy and the Importance of Multicultural Research

When conducting research, culturally competent professional counselors recognize the importance of multiculturalism, diversity, social justice, and advocacy in research contexts, designs, processes, outcomes, and dispersal.

\section{Professional counselors should:}

- increase knowledge, skills, and awareness on an ongoing basis in the areas of multiculturalism and advocacy. Examples may include, but are not limited to, attending professional conferences, engaging actively in self-reflective practices, confronting experiences of privilege and oppression, seeking and being open to feedback from other professionals and peers, and reviewing recent multicultural literature and research;

- promote advocacy efforts on the micro, meso, and/or macrolevel (American Counseling Association [ACA], 2003); 
- engage in advocacy efforts to include diverse and marginalized populations in all research (Rencher \& Wolf, 2013; Rogers \& Lange, 2013). Special consideration should be given to the source of vulnerability to avoid unnecessary stereotyping and/or inadvertently and unjustifiably excluding individuals due to misguided protection (Rogers \& Lange, 2013);

- recruit and retain diverse faculty and students in counselor education programs. This is particularly relevant for counselor educators and administrators. The participation of researchers of diverse backgrounds is valuable; however, it is the responsibility and obligation of all researchers to conceptualize and conduct research that is multiculturally inclusive and responsive;

- foster the development of multiculturally competent researchers. This includes researchers who are developing interests and skills in multicultural research or in general research with multicultural considerations;

- encourage greater diversity and multicultural representation on institutional review boards (IRBs; Rencher \& Wolf, 2013);

- attempt to increase the number of multicultural researchers in general, which can ultimately be done through flexibility in how research is conceptualized and carried out and can further help to increase minority participation (Coakley et al., 2012; Palafox, Buenconsejo-Lum, Riklon, \& Waitzfelder, 2002; Rencher \& Wolf, 2013); and

- adhere to the 2014 ACA Code of Ethics with particular attention to Section G. Research and Publication (ACA, 2014).

\section{Research Goals and Design}

The creation of research goals and questions must reflect multicultural intentionality and inclusiveness. Professional counselors examine their own biases, the biases of their research teams, and the biases of other involved parties prior to (and throughout) engaging in research.

Professional counselors should:

- consider, while designing a research study, if the process will establish empirically supported treatments and/or culturally sensitive treatments (Chang, Hays, \& Gray, 2010);

- explore emic and etic perspectives related to their research and research questions (Cokley \& Awad, 2008);

- thoroughly explore their rationale for conducting multicultural research (Chang et al., 2010). Ensure that research conducted validates and expands knowledge of diverse and marginalized client populations, while understanding how constructs are conceptualized across contexts;

- conduct research that promotes cultural awareness and advocacy and/or increases external validity of studies (Chang et al., 2010);

- consider topics that will increase multiculturalism in research. Examples include, but are not limited to, cultural identity development and the promotion of cultural identity development; social justice research; the impact of multicultural competencies on counseling services and counselor education; intersectional identities and the impact of those identities on the person, the community, and the counseling relationship; indigenous populations and methodologies; increased qualitative and mixed-methods 
research to explore participant lived experiences (Cokley \& Awad, 2008; Hays, Milliken, \& Randall, 2014);

- understand that the research itself must be multidimensional, addressing the research goals, the community, and community interrelations (Robinson \& Trochim, 2007);

- avoid biased studies that traditionally use a comparative design (inappropriate proxies to compare groups or apply findings in a pathologizing manner; Cokley \& Awad, 2013);

- ensure that research is compliant with the 1993 National Institute of Health (NIH) Revitalization Act (PL 103-43; 42 USC 298a-1), requiring the inclusion of women and racial/ethnic minorities in research and for researchers to become sensitized to the needs of these groups (NIH, 2001);

- understand how the Common Rule (45 CFR 46.111(b)) and the requirement that IRB provide additional safeguards for participants who may be classified as vulnerable (e.g., children, prisoners, pregnant women, those with mental disabilities, economically or educationally disadvantaged persons) will impact their research design and participant selection (U.S. Department of Health and Human Services, 2016);

- consider the extent to which a population is actually benefiting from the research by weighing the benefits/risks to the researchers versus the benefits/risks to the participants. Also consider the extent the research is decolonizing or challenging the cultural influence of those with power and privilege;

- avoid proximal variables when possible (e.g., group membership) for more distal variables (e.g., socioeconomic status, collectivism, gender identity; Cokley \& Awad, 2008, 2013);

- consider and determine whether there are vulnerabilities that researchers are causing within the design itself (e.g., financial incentives as potentially exploitive);

- consider including participants as coresearchers in the study; and

- address cultural validity in addition to other validity issues (Cokley \& Awad, 2008).

\section{Research Process}

Professional counselors select research and data collection methods that are the most effective for diverse and marginalized populations. Researchers select methods that empower participants and work to avoid exploiting participants' status(es) or anonymity. In addition, researchers attend to the power dynamics in the researcher-participant relationship.

\section{Professional counselors should:}

- make research a two-way learning process; that is, the researcher and the participant both gain knowledge from engaging in the research (Hays et al., 2014);

- engage with participants' communities to encourage their involvement throughout the research process (Coakley et al., 2012; Rothstein, 2013). This community involvement should be encouraged during each phase of research including research question development, research design (e.g., community-based action research), data collection, analysis, publication, and presentation;

- gain extensive information about the community they seek to investigate (Hays et al., 2014); 
- maintain personal contact with the community before, during, and after the research process (e.g., member checking and prolonged engagement; Hays et al., 2014);

- remember the four Rs of indigenous research practices: reciprocity, rights and determination, responsibility, and respect (Kovach, 2009; Smith, 2012) and consider implementing indigenous research practices as appropriate;

- assess participants' previous experiences with research and their concerns and potential mistrust of researchers (who may have engaged in colonizing practices); and

- remember that the awareness and competence of the researcher/research team determines whether research is multiculturally competent, not a specific methodology (Palafox et al., 2002; Ponterotto, Mathew, \& Raughley, 2013).

\section{Literature}

Professional counselors conduct thorough literature reviews that include relevant multicultural references that accurately and equitably represent participant populations.

Professional counselors should:

- consider how and why certain literature has been categorized as multicultural. Because multicultural research has been defined differently in previous literature, it is important (as researchers establish a study rationale and/or consume the research) to reflect on what groups have or have not been included in multicultural research; and

- consume literature critically: Analyze literature for methodological flaws, participant oppression and/or exploitation, and the method in which minority groups were/are portrayed in the literature. Literature has typically compared racial/ethnic groups without context (Hays et al., 2014).

\section{Participants and Procedures}

Professional counselors select research procedures that are multiculturally competent, minimize participant risk, and provide for equitable participant representation. Researchers strive to recruit and integrate participants with varied and/or underrepresented characteristics in order to conduct and produce research that is multiculturally responsive and sound.

Professional counselors should:

- $\quad$ increase focus on intersecting identities and those outside of race/ethnicity (Fisher \& Kalbaugh, 2011; Hays et al., 2014);

- determine whether they are taking an etic versus emic approach to research (see Chang et al., 2010; Palafox et al., 2002);

- remember that convenience sampling tends to be the predominant sampling method, which may not include certain populations due to access issues. Active efforts should be made to recruit and include diverse and generalizable participants;

- offer noncoercive incentives to participants; 
- consider extending the Common Rule to racial/ethnic minorities, as they may be considered vulnerable in certain circumstances. It is important, however, to not stigmatize the population in this conceptualization (Rencher \& Wolf, 2013);

- identify alternative ways to communicate research goals and obtain consent when literacy issues or differences in language and communication are present (Rogers \& Lange, 2013);

- engage communities in regard to sampling; this may include developing community advisory boards, pilot testing, using action research processes, consulting with a community elder/leader, and seeking a community versus individual voice (Coakley et al., 2012; Cokley \& Awad, 2013; Kelley, Belcourt-Dittloff, Belcourt, \& Belcourt, 2013; Kovach, 2009; Palafox et al., 2002; Robinson \& Trochim, 2007; Smith, 2012); and

- implement recruitment strategies that address possible minority distrust of research and researchers (Fisher \& Kalbaugh, 2011; Robinson \& Trochim, 2007; Rothstein, 2013).

\section{Measures}

Culturally competent professional counselors recognize that any measures or assessment tools used must be appropriate for the participant population.

Professional counselors should:

- $\quad$ increase complex assessment of variables versus using typical, simpler variables to help reduce faulty measurement;

- reduce insufficient and/or minimal norms or other test construction issues. Constructs may have different meanings to individuals (Hays et al., 2014); and

- be aware that not all assessments are appropriately normed for diverse or marginalized populations and samples; qualitative methods may be a more multiculturally sound way to conduct research with minority and/or underrepresented populations.

\section{Data Analysis}

Data analysis procedures selected by culturally competent professional counselors allow for increased accuracy and decreased bias in the portrayal of participant experiences and responses.

Professional counselors should:

- explore their biases throughout data analysis; working with a diverse research team can help limit researcher bias;

- member check when methodologically appropriate; and

- consider peer debriefing to limit researcher bias and gain outside perspective; debriefing with diverse colleagues can assist in challenging researcher bias.

Findings and Applications

Professional counselors present research findings in a way that accurately reflects participant data and experiences. Researcher bias is limited and reflexivity is of importance. 
Professional counselors should:

- avoid comparison of groups (often to indicate superiority of one over another), and if comparing groups provide a rationale that does not further disenfranchise groups (Cokley \& Awad, 2013; Rothstein, 2013);

- attempt to publish manuscripts and present findings to disperse research that is multiculturally responsive;

- formulate empirical constructs to reflect values or experiences of marginalized populations (Cokley \& Awad, 2013);

- avoid incompetent multicultural practices that could lead to misinterpretation (and thus misapplication) of findings (Hays et al., 2014; Palafox et al., 2002; Rothstein, 2013); and

- develop practical applications for their findings that will inform professional counseling practices.

\section{Authors' Note}

In 2013, the Executive Council of the Association for Assessment and Research in Counseling (AARC) charged the Diversity Committee with the task of developing the Standards for Multicultural Research. The goal was to construct a set of standards that promote cultural intentionality, inclusivity, and responsiveness in research.

\section{References}

American Counseling Association . (2003). Advocacy competencies. Alexandria, VA: Author. Retrieved from http://www.counseling.org/docs/competencies/advocacy competencies.pdf?sfvrsn=3

American Counseling Association . (2014). Code of ethics. Alexandra, VA: Author.

Chang, C. Y., Hays, D. G., Gray, G. (2010). Multicultural issues in research. In Sheperis, C., Young, J. S., Daniels, M. H. (Eds.), Counseling research: Quantitative, qualitative, and mixed methods (pp. 262-274). Boston, MA: Pearson.

Coakley, M., Fadiran, E. O., Parrish, J., Griffith, R. A., Weiss, E., Carter, C. (2012). Dialogues on diversifying clinical trials: Successful strategies for engaging women and minorities in clinical trials. Journal of Women's Health, 21, 713-716. doi:10.1089/jwh.2012.3733

Cokley, K., Awad, G. H. (2008). Conceptual and methodological issues related to multicultural research. In Heppner, P. P., Wampold, B. W., Kivlighan, D. M. (Eds.), Research design in counseling (3rd ed., pp. 366-384). Belmont, CA: Thomson Brooks Cole.

Cokley, K., Awad, G. H. (2013). In defense of quantitative methods: Using the "master's tools" to promote social justice. Journal for Social Action in Counseling and Psychology, 5, 26-41. 
Fisher, J. A., Kalbaugh, C. A. (2011). Challenging assumptions about minority participation in US clinical research. American Journal of Public Health, 101, 2217-2222.

doi:10.2105/ajph.2011.300279

Hays, D. G., Milliken, T. F., Randall, J. (2014). Themes and future directions in multicultural counseling theory, ethics, practice, and research. In Hays, D. G., Erford, B. T. (Eds.), Developing multicultural counseling competence: A systems approach (2nd ed., pp. 529-542). Boston, MA: Pearson.

Kelley, A., Belcourt-Dittloff, A., Belcourt, C., Belcourt, G. (2013). Research ethics and indigenous communities. American Journal of Public Health, 103, 2146-2155.

doi:10.2105/ajph.2013.301522

Kovach, M. (2009). Indigenous methodologies: Characteristics, conversations, and contexts. Toronto, Canada: University of Toronto Press.

National Institute of Health . (2001). NIH guidelines on the inclusion of women and minorities as subjects in clinical research. Retrieved from https://grants.nih.gov/grants/funding/women_min/guidelines_amended_10_2001.htm

Palafox, N. A., Buenconsejo-Lum, L., Riklon, S., Waitzfelder, B. (2002). Improving health outcomes in diverse populations: Competency in cross-cultural research with indigenous Pacific Islander population. Ethnicity \& Health, 7, 279-285. doi:10.1080/1355785022000060736

Ponterotto, J. G., Mathew, J. T., Raughley, B. (2013). The value of mixed methods designs to social justice research in counseling and psychology. Journal for Social Action in Counseling and Psychology, 5, 42-68.

Rencher, W. C., Wolf, L. E. (2013). Redressing past wrongs: Changing the common rule to increase minority voices in research. American Journal of Public Health, 103, 2136-2140. doi:10.2105/ajph.2013/301356

Robinson, J. M., Trochim, W. M. K. (2007). An examination of community members', researchers', and health professionals', perceptions of barriers to minority participation in medical research: An application of concept mapping. Ethnicity and Health, 12, 521-539. doi:10.1080/13557850701616987

Rogers, W., Lange, M. M. (2013). Rethinking the vulnerability of minority populations in research. American Journal of Public Health, 103, 2141-2146. doi:10.2105/ajph.2012.301200

Rothstein, M. A. (2013). Editor's choice: Ethical research and minorities. American Journal of Public Health, 103, 2118. doi:10.2105/ajph.2013.301390

Smith, L. (2012). Decolonizing methodologies (2nd ed.). London, England: Zed Books. 
U.S. Department of Health and Human Services . (2016). Federal policy for the protection of human subjects ('common rule'). Retrieved from http://www.hhs.gov/ohrp/regulations-andpolicy/regulations/common-rule/index.html 